\title{
Nuevas evidencias incas entre Collahuasi y Río Frío (I y II Regiones del norte de Chile)
}

ThOMAS F. LYNCH ${ }^{1}$ Y LAUTARo NÚÑ̃Z ${ }^{2}$

\section{RESUMEN}

El llamado "gran despoblado", se sitúa en un inmenso desierto de altura, con escasa agua y casi totalmente desocupado, pero rico en vestigios bien conservados tanto de los períodos prehistóricos tempranos como tardíos. Desafortunadamente, la explotación de sus recursos en la actualidad, especialmente la exploración y desarrollo de su riqueza minera, amenaza sus delicados caracteres superficiales y por lo tanto requiere de un rápido registro. Por eso, hemos trabajado en torno a la ocupación inca, en proyectos originalmente vinculados con el uso arcaico de las cuencas de Atacama y Punta Negra. La presencia inca hacia el sur, especialmente en el Norte Chico, es conocida por los estudios pioneros de Iribarren y Bergholz (1971), Niemeyer y Silva (1977), Rivera e Hyslop (1984) y, más recientemente, a través del trabajo de Stehberg y Carvajal (1988). En esta oportunidad se presentan nuevas evidencias correspondientes al sector Collahuasi-Río Negro, en las tierras altas de la I y II regiones de Chile, como un avance preliminar del Proyecto Inca patrocinado por The National Geographic Society.

\section{ABSTRACT}

The northern part of Chile, called "gran despoblado", is located in a immense and high desert with scarse water and totally unpopulated, but it has wellkept remains belonging both early and late prehistoric periods. Unfortunately, the present working and development of its mineral wealth threaten its fine superficial features and it has to be recorded as soon as possible. For that reason we have worked around the inca occupation, we have worked in projects originally related to the arcaic use of the Atacama and Punta Negra basins. The inca presence towards the south lands, specially in the Norte Chico, is known through the pioneer investigation carried out by Iribarren and Bergholz.(1971), Niemeyer and Silva (1977), Rivera and Hyslop (1984) and recently through the study made by Stehberg and Carvajal (1988). In this opportunity new evidences belonging to the Collahuasi area-Río Negro, in the highlands of the first and second regions are shown, and also the preliminary advance of the Inca Project by The National Geographic

1 Institute of Andean Research. 630 Mt. Pleasant Road, Freeville, New York 13068, ESTADOS UNIDOS.

2 Instituto de Investigaciones Arqueológicas y Museo R. P. Gustavo Le Paige, s. j., Universidad Católica del Norte, San Pedro de Atacama, CHILE.
Society. This essay constitutes a synthesis of the preliminary results of an investigation of the Inca Road, its exact route, structures, and purpose, as supported by The National Geographic Society (4654-91, Mapping inca installations in the Atacama: Relations with local peoples). Attention has focussed on Catarpe Tambo, which appears to have been an administrative center for the road complex between at least $22^{\circ}$ and $25^{\circ} S$ Lat. Large parts of the system between Turi and Chiu Chiu in the north, and Río Frío in the south, were located and recorded by the authors, specially from 1991 through 1993. Abandoned after the Inca Period, Catarpe evidences storage, metallurgy, protective fortifications, ritual, concentration of precious goods, and even administrative functions (quipu) that are often absent at the smaller tambos. Much of the road system was rerouted during the Spanish Period, so that it could be traversed by groups with horses and mules, leaving other, subsequently unused parts of the original Inca Road inperfect condition. Untrodden portions of the original roadway often feature distinctive intact hitos, curbing stones, stairs, and associated artifacts such as pottery and sandals.

\section{La identificación de postas y caminos desde Catarpe a Río Frío}

\section{Catarpe}

Aunque el primer autor comenzó las excavaciones en Catarpe, un tambo inca y centro administrativo en 1976 (Lynch 1978), éstas fueron precedidas por un reconocimiento llevado a cabo por Mostny (1948) y las excavaciones de un cementerio realizadas por Le Paige (1972-73). En los años 1980 y 1981, Hyslop, Niemeyer, P. Núñez, Rivera, Sanhueza y Schmidt (en adelante, el equipo Camino del Inka) investigaron parte de un segmento norte-sur de este camino entre los $23^{\circ} 30^{\prime}$ y $25^{\circ} 30^{\prime}$ Lat. S (aproximadamente entre Socaire y Vaquillas), inmediatamente al sur del Gran Salar (Niemeyer y Rivera 1983; Hyslop 1984; Hyslop y Rivera 1984). Además, en 1983, Rivera trabajó con el primer autor por unos días en Catarpe, como lo hizo Sanhueza en 1976 y 1983, identificándose y explorándose un segmento del Camino del Inka que llega esta vez al Tambo Catarpe desde el noreste (Figuras 1 y 2). 
Catarpe es el tambo de mayor tamaño y el diseñado más clásicamente, ubicado muy estratégicamente en la frontera de Atacama. Es un sitio obviamente importante y recibirá por supuesto más estudios. Alrededor de 200 cuartos y estructuras cubren cerca de 2 ha, de manera que el trabajo recién ha comenzado, aunque Le Paige y otros parecieran haber agotado las inhumaciones en el área del cementerio. Se emplaza sobre tres restos de terrazas pertenecientes al Pleistoceno a lo largo de la orilla de la llanura fluvial del río San Pedro, alrededor de $7 \mathrm{~km}$ hacia el norte o río arriba de la actual

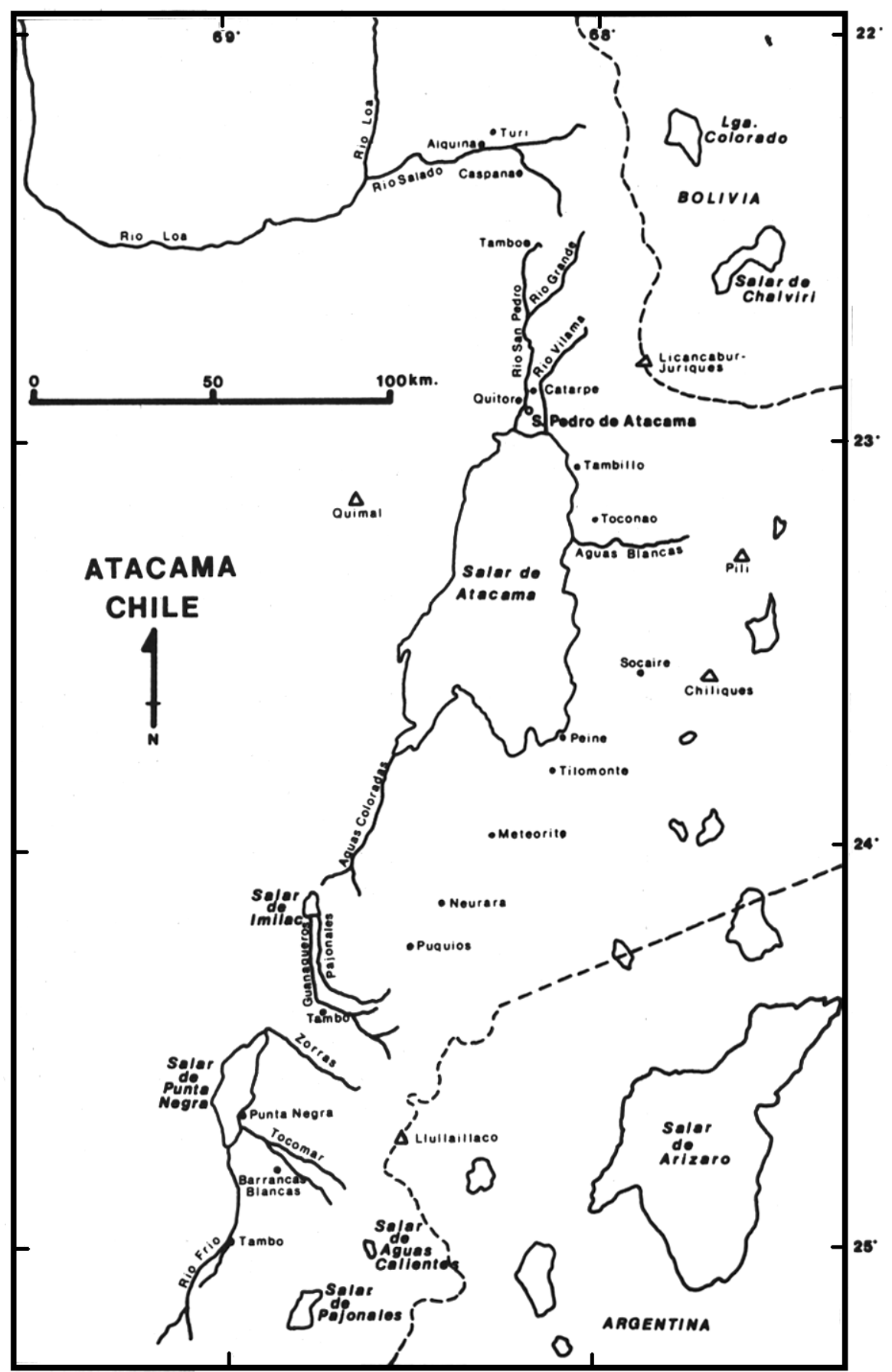

Figura 1. Localización de sitios arqueológicos entre Turi y río Frío. 


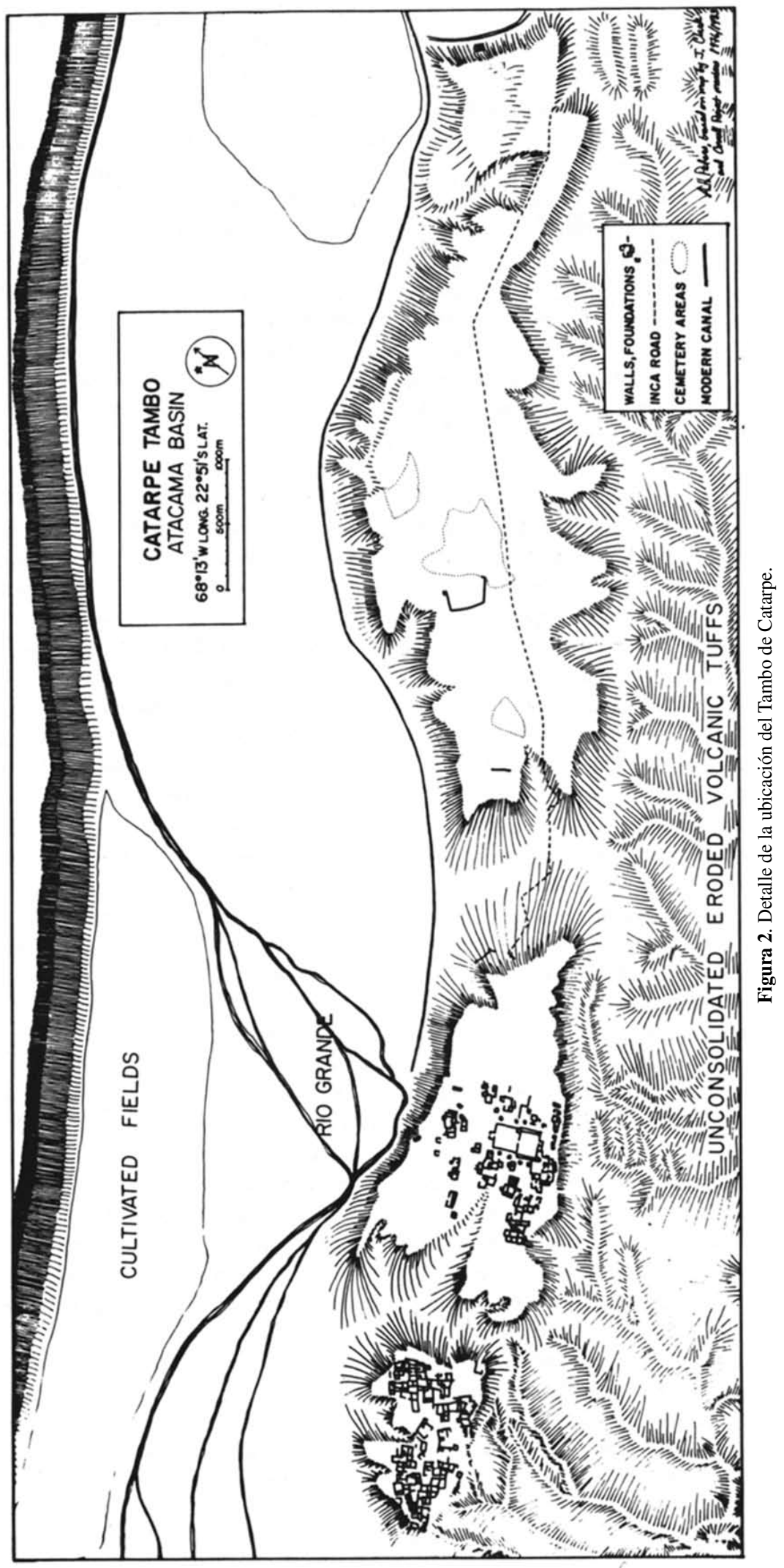


plaza de San Pedro de Atacama. En la época de los incas el sitio probablemente controló gran parte del abastecimiento de agua y una ruta importante al altiplano boliviano-peruano.

La ubicación estratégica es sugestivamente paralela al actual Destacamento del Ejército que a una distancia igual asciende el río Vilama y también por el borde y no por el interior de la población agrícola y comercial. Los campos de Catarpe reciben la primera irrigación y así producen las mejores cosechas, mientras que aún el antiguo Camino del Inka, sin un chasquihuasi activo ni estaciones aduaneras, sigue siendo la ruta preferida para el intercambio de coca boliviana por chañar chileno y las llamas vuelven a ser un importante, pero ilegal artículo de comercio y transacciones.

El antiguo transporte de turquesa chilena ha cesado, pero ahora el cobre se transporta en camiones y en otras vías por otros caminos: la labor minera local siempre ha sido importante. La presencia arqueológica de oro, de artefactos de cobre, fragmentos de planchas y crisoles, cobre deformado e incluso escoria, en Catarpe y no en otros tambos de la zona, destaca más nuestra propuesta de que Catarpe es mucho más que un tambo, tal como se le denomina ahora más por razones de tradición que por estudios detallados.

En efecto, Niemeyer y Schiappacasse (1988: 15456) han decidido de manera similar que Catarpe es "uno de los centros administrativos más importantes descubiertos en el territorio chileno", desde el cual los incas planearon y organizaron la conquista del valle de Copiapó y las regiones de más al sur. Ellos clasifican a Catarpe como una pequeña ciudad o pueblo y, siguiendo a Ruppert (1984), proponen que la turquesa de El Salvador y otras minas del sur fueron enviadas a través de Catarpe a otros lugares de Bolivia y Argentina, aunque esto supera la evidencia que demuestra que sólo pequeñas cantidades de turquesa se han descubierto, aún lejos de Catarpe mismo, y que no existen muchas razones para ver el oasis de San Pedro de Atacama como "un centro de fabricación de adornos de turquesa"; sin embargo, diríase que uno puede seguir el Camino del Inka a través del "gran despoblado" por las turquesas esparcidas, tal como lo hicieron Hansel y Gretel cuando siguieron aquel camino que tenía migajas de pan dispersas... Tal vez la turquesa fue transbordada o remitida a través de Catarpe, pero no fabricada o modificada allí, o tal vez todavía no hemos descubierto sus talleres.

A partir de las aún limitadas excavaciones del primer autor, llevadas a cabo en los años 1976, 1983 y 1985 , queda de manifiesto que el cobre fue trabajado en Catarpe o cerca de allí. También se piensa lo mismo del oro, pero estas pequeñas hojas descubiertas en Catarpe bien pueden haber sido llevadas desde algún otro lugar. Por otra parte, la escoria, el metal de cobre deformado y fragmentos de planchas biválvicas ennegrecidas y de crisoles, sugieren una verdadera metalurgia de cobre in situ. El crisol de Catarpe, aunque incompleto, se asemeja a otro del valle de Copiapó descrito por Niemeyer (1981).

De todos los artefactos de cobre acabados, tal vez los más interesantes son los de dos placas de cobre o golas (gorguillas) de alrededor de $10 \mathrm{~cm}^{2}$ y $2 \mathrm{~mm}$ de grosor, con diseños afiligranados muy bien ejecutados, de rostros humanos y cuadrúpedos distribuidos por ambos lados (Figura 3). Fueron descubiertas adheridas junto a unas pinzas para depilar. Es difícil esclarecer o contribuir en algo en este sentido frente a estas piezas, pero sí nos preguntamos cómo vinieron a dar a Catarpe estas placas tan importantes y por qué el rostro humano en algunos casos aparece con los ojos cerrados, diferente a los ojos abiertos del anverso. De acuerdo a A. R. González (com. pers. 1984), las placas de Catarpe son muy similares o casi idénticas a otras descubiertas en Rinconada (Jujuy, Argentina). Pertenecen a una pervivencia del estilo Aguada que se remonta a tiempos anteriores al de los incas, pero el diseño antropomorfo (rostro y unku moteado) pertenece al estilo Santa María también del Noroeste Argentino, que efectivamente es sincrónico al final con la expansión inca. Placas algo similares llegaron a usarse incluso durante tiempos hispánicos tempranos.

Por otra parte, en 1988, el arqueólogo Torres Montecinos descubrió una placa que se asemeja a aquéllas descubiertas en Catarpe, también de $10 \mathrm{~cm}^{2}$. Las encontró en un tumba cercana al Templo del Agua (o depósito) en Sacsahuamán (Ascué 1988). Este ejemplar también estaba acompañado de un "depilador de barba". En el contexto inca de Cusco, los ojos abiertos insertos en el rostro humano son considerados una representación del sol, mientras que los animales cuadrúpedos son vistos como felinos. La serpiente de dos cabezas es un motivo 


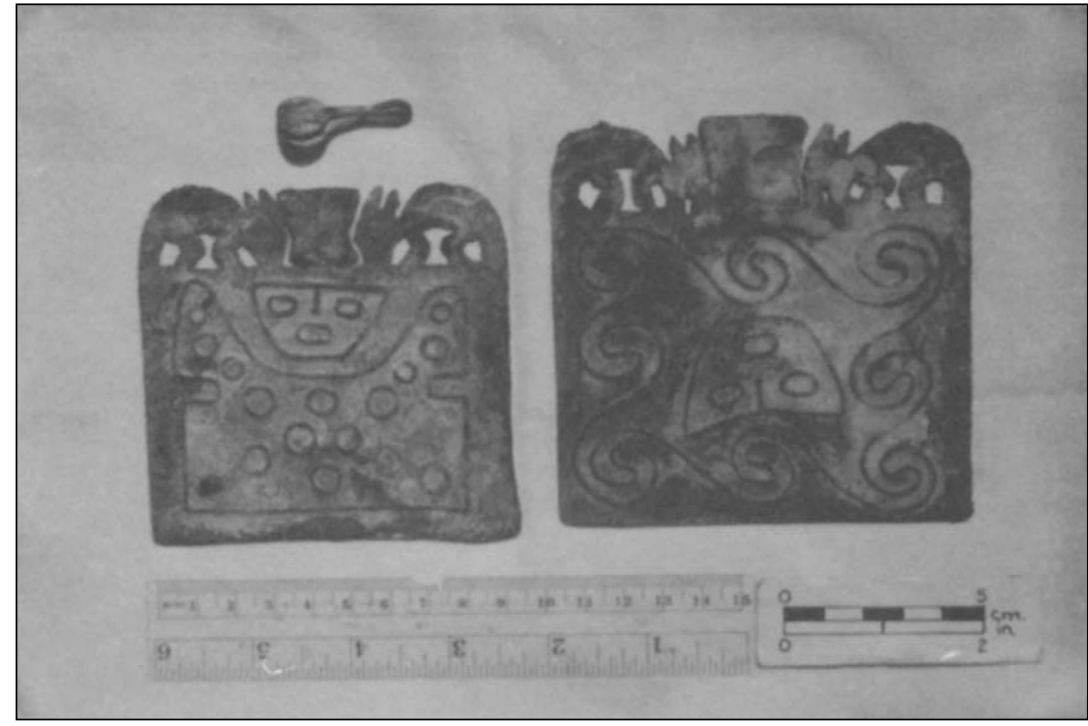

Figura 3. Placas y pinza de Catarpe. Se advierte el estilo Santa María-Inca.

adicional proveniente de los Andes Centrales, pero, viendo la fotografía del periódico, pareciera que la placa cusqueña también pertenece al estilo Santa María-Aguada.

En relación al proceso de manufacturación local como tributación, Niemeyer y Schiappacasse (1988: 156) han propuesto que, así como en Humahuaca, Catarpe pudo haber incluido un taller en donde los artesanos locales transformaban materiales preciosos y semipreciosos en objetos de prestigio y adornos, siguiendo los modelos incas más deseados o requeridos. Hasta ahora no tenemos evidencia de esto. Tampoco hemos comprobado sus afirmaciones que establecen que Catarpe fue el centro desde el cual los agentes incas dirigieron la construcción de los altares localizados en la cima de la cordillera: Licancabur-Yariques, Chiliques, Pili, Pular, Llullaillaco y Quimal. Aunque otras investigaciones realizadas por escaladores y arqueólogos han establecido plenamente que estos altares son incas y constituyen rasgos rituales importantes (Le Paige 1978; Reinhard y Sanhueza 1982; Reinhard 1983, 1985).

Hyslop (1990: 240) ha advertido que cualesquiera sean sus connotaciones simbólicas, la mayoría de las plazas de cuatro lados constituyen colonias o instalaciones administrativas fuera del área de Cusco. Setenta $\mathrm{km}$ al norte de Catarpe se ubica el centro inca de Turi, aunque el primer autor en 1992 descubrió un pequeño tambo a mitad de camino entre Turi y Catarpe, donde el Camino Inka penetra al río Salado (Figura 4), un tributario del río San Pedro de Atacama (cancha de fina albañilería de piedras asociadas al camino). Turi presenta en una escala comparable entre una plaza inca o cancha y una gran kallanka, orientadas de manera similar (Castro y Cornejo 1990). Hacia el sur, la distancia al próximo centro administrativo es por lo menos cinco veces superior (más de $400 \mathrm{~km}$ ), con nada conocido que sea más grande que Catarpe, entre un punto y otro, probablemente porque el camino pasó por una de las zonas más áridas y despobladas de los Andes (Hyslop 1990: 253-254, 279). En efecto, La Puerta, todavía más lejos en dirección al sur, en el valle de Copiapó, es casi del mismo tamaño (aproximadamente 200 recintos) y tiene una cancha un poco más grande, con un trazado casi idéntico, habitaciones conjuntas en los dos lados opuestos a la plaza y tres recintos de "almacenaje" a lo largo de un tercer sector.

Turi, Catarpe y La Puerta son todos aparentemente estaciones administrativas ubicados a lo largo del camino principal que va de norte a sur. Estuvieron situados dentro o cerca de poblaciones indígenas, subsistiendo con los recursos pastoriles y agrícolas relativamente generosos: la vega de Turi, el río Salado Superior, los oasis de San Pedro de Atacama y los abundantes recursos del valle de Copiapó. Las señales de metalurgia en Catarpe y sus vetas de San Bartolo son paralelas también a la mina inca de Caspana (un poco más arriba de 


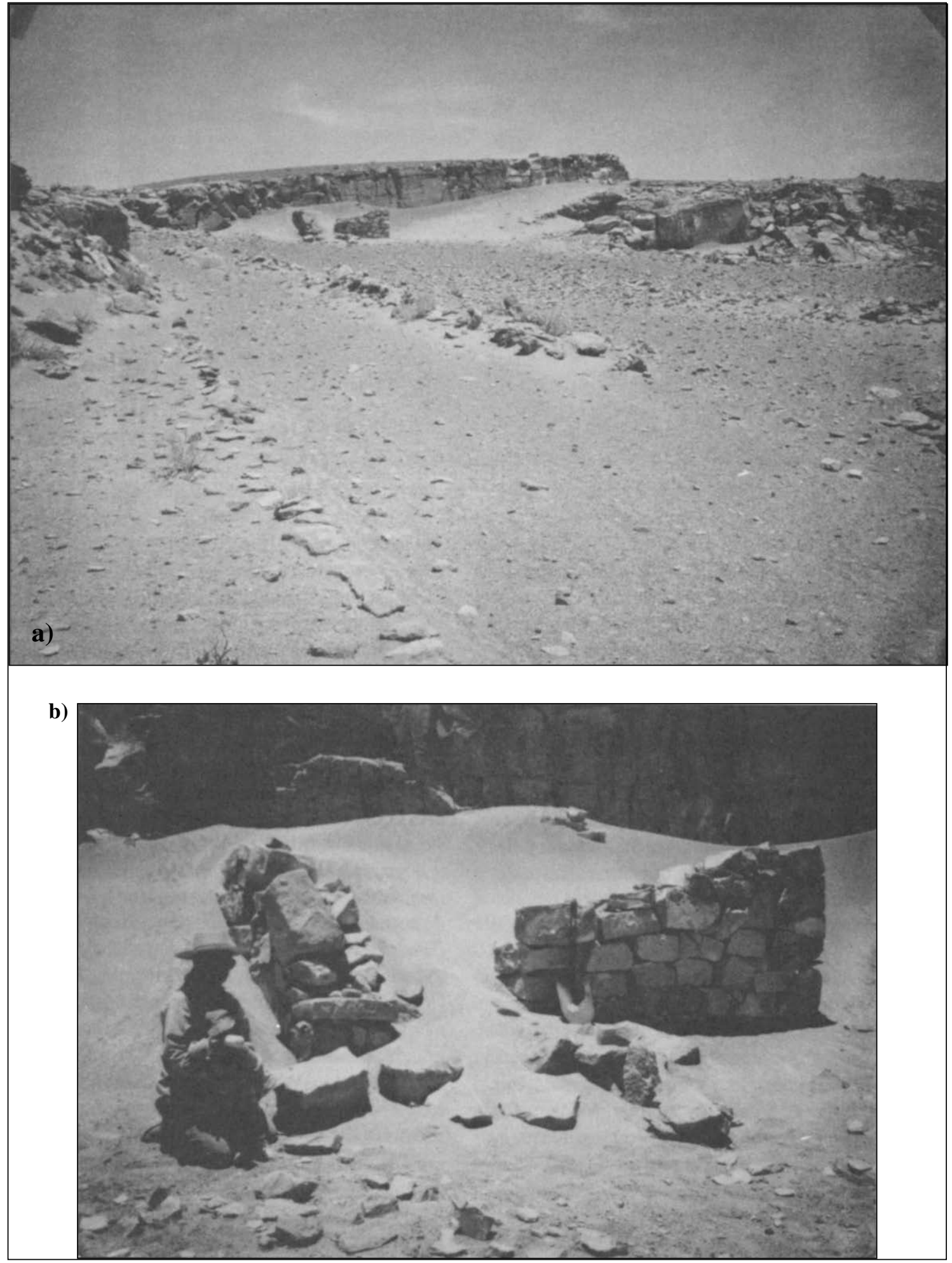

Figura 4. a) Camino inca de acceso a Tambo Salado entre Turi y Catarpe; b) detalle de un chasquihuasi. 
Turi), a Collahuasi (de acuerdo al segundo autor) y la relativa proximidad de La Puerta a y su supuesto control sobre la fundición de cobre llamada Viña del Cerro. Efectivamente, Niemeyer concluyó que La Puerta fue el principal centro administrativo inca en el valle de Copiapó (Hyslop 1990: 252). En general, de acuerdo con Hyslop (1990: 270-279), los centros administrativos incas se establecían con miras a controlar varios asuntos, tales como los ambientales, culturales y políticos. Estos incluían acceso a tierras, agua y otros recursos naturales, jerarquizándose la ubicación estratégica a lo largo de las principales rutas en o preferentemente cerca de las concentraciones de grupos étnicos locales. A propósito, estamos tentados por volcar la interpretación usual que surge sobre el tema y visualizar la penetración inca como un enlace de centros administrativos, no como núcleos con alta densidad demográfica, que a menudo se traza a un costado de las rutas laterales (Lynch 1989: 7). Siguiendo esta línea de razonamiento, podríamos esperar que los centros administrativos fueran construidos de acuerdo a una fórmula, o plan maestro, en vez de que fueran grandes pueblos arraigados. Dado el gran origen artificial y los propósitos políticos de estos centros administrativos no es raro que muchos de ellos fueran abandonados poco después de la invasión europea acelerándose su destrucción.

Hasta ahora, el primer autor no ha descubierto bienes o utensilios europeos en Catarpe, ningún trozo de hierro, alfarería vidriada o vasos rotos, pero el segundo autor ha constatado que un pequeño cementerio inca-altiplánico con ollas de pedestal se correlaciona con asentamientos incas establecidos entre los algarrobales de la Hostería de San Pedro de Atacama, portadores de las primeras cuentas de vidrios europeas, como un evento tal vez post Catarpe. Puede ser que Catarpe fuera abandonado, como se especuló anteriormente, cuando el Camino del Inka fue recorrido por los conquistadores Diego de Almagro (1536) y después Pedro de Valdivia (1540-41). Al respecto, una conjetura unánime señala que el fuerte o pucara tomado por Francisco de Aguirre, que ellos más adelante denominaron "las cabezas" en honor a los trofeos sangrientos que desplegaron, es el mismo que en la actualidad se conoce como Pucara de Quitor. Para el primer autor esta identificación, sin embargo, se basa fuertemente en la opinión de Le Paige, quien señaló que los españoles habían quemado el fuerte durante o después de la toma (Hidalgo 1972: 32-35). Mientras Quitor pueda mostrar señales de haber sido incendiado y Catarpe no muestre nada, la batalla descrita por la principal fuente de información, Gerónimo de Bibar (1966 [1558]), tal como lo interpretó Hidalgo, podría aplicarse a cualquiera de los dos sitios: el fuerte tomado por Aguirre estaba situado en una colina alta y era accesible por un sendero único, según Bibar. Siguiendo con el primer autor y su espíritu nacionalista catarpeño, la descripción de Bibar sobre la batalla se ajusta tanto a Catarpe como a Quitor. Este último fuerte está a más altura, pero Catarpe también tiene trabajos defensivos, está en una planicie y puede ser invadido fácilmente una vez que se llega a la cumbre. El ascenso a Quitor puede realizarse a través de un costado único pero amplio; a Catarpe se puede acceder por caminos o senderos angostos y difíciles, vigilados por emplazamientos en los que encontramos numerosas flechas pequeñas, constituyendo registros relativamente comunes en Catarpe. El primer autor reconoce haber guiado a tantos grupos de estudiantes, colegas y visitantes por ambos ascensos, oportunidad en que todos han subido cargados como los españoles y dudaría en decir cuál de los dos sitios podría haber sido el de "las cabezas" del siglo XVI. El segundo autor, de espíritu nacionalista quitoreño, después de serias cavilaciones aplicó el célebre método etnolingüístico, le consultó a un español sabio cuál de los dos era un "cerro agrio" y se escuchó claro: Quitor. Además, como hasta ahora hay que saltar un gran muro defensivo, entre piedras para hondas y ruinas con algunos recintos incas, es que allí estaba el poder atacameño y con ello también la "gloria"...

\section{Catarpe en un contexto comparativo}

Siguiendo a Henderson $(1987,1992)$ podemos auscultar que existe un aliciente, cuando se trabaja en la periferia de una cultura de peso y de por sí muy conocida, para asumir homogeneidad en el centro cultural y tratar más de cerca con la "arqueología de margen", en términos de comparaciones y contrastes más visibles en relación a un Estado o Cultura Inca implícitamente monolítico. En verdad, existe una "tendencia natural de enfocar similitudes externas e interpretarlas en términos de interacción" (Henderson 1987: 455). Si existen similitudes y diferencias no nos gustaría enfatizar ni evaluarlas comparativamente en los contextos de este centro administrativo supuestamente importante versus los simples tambos, caminos y puestos de control dispuestos a un costado del camino o por los hitos 
que marcan las jornadas del caravaneo. Desde luego, las diferencias entre marca, tambo, chasquihuasi, apacheta, hitos, etc., sacuden las advertencias de Henderson y deben ser cotejadas con las evidencias arqueológicas meridionales.

Sea como fuere, Catarpe comparte un sinnúmero de caracteres con otras instalaciones incas, pero solamente algunas con Cusco y el área central inca. Lo más destacable de esto último es la orientación de la cancha, $63^{\circ}$ a $66^{\circ} \mathrm{E}$ del norte verdadero. Esencialmente es igual a las orientaciones del
Qoricancha en Cusco y de la plaza trapezoidal y la análoga cancha qori, un terreno rectangular localizado al sureste en Incahuasi. Para Hyslop (1985: 60-66, 1990: 232-237) éstas son alineaciones astronómicas significativas, aunque Dearborn (1986) ha hecho más preguntas concernientes a su precisión y utilidad. Nuestra propuesta es que Catarpe responde a un patrón cusqueño de plaza doble rodeada de múltiples recintos rectangulares y cuadrangulares como aquella llamada Checollopata presentada por I. Farrington en el reciente XI Congreso de Arqueología Argentina (Figura 5).

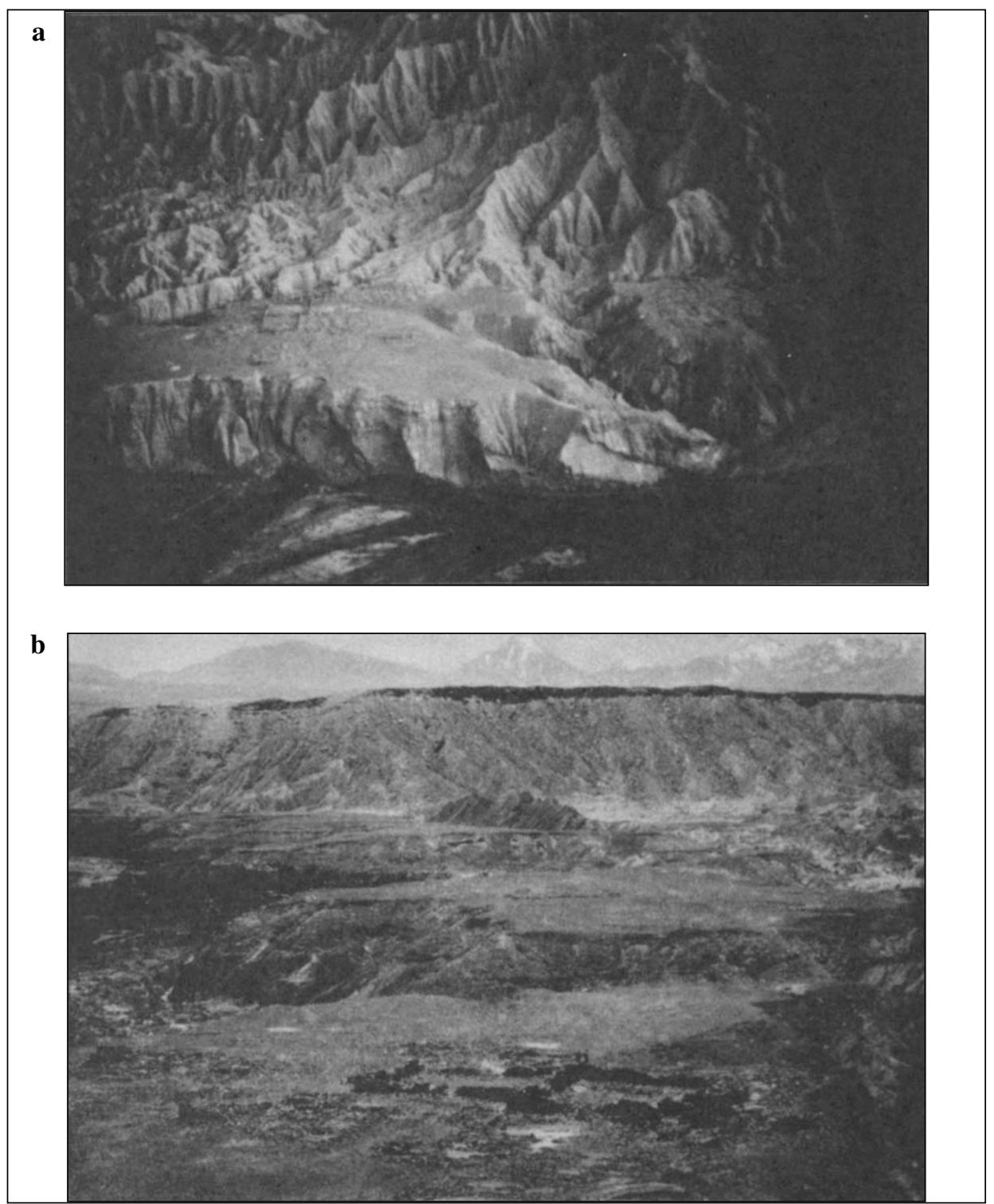

Figura 5. a) Visión aérea del Tambo de Catarpe donde se destaca la doble cancha nuclear; b) Detalle de la doble cancha. 
Estamos de acuerdo con la conclusión de Hyslop (1990: 234-243), aunque hicieran o no los incas sus alineaciones y medidas extremadamente precisas para sus observaciones astronómicas, aquella que decía que posiblemente orientaban los edificios y las plazas hacia los azimuts para simbolizar y definir conceptos en cosmología, estructura social y estaciones calendarias. Las orientaciones que se intentaron pueden haber estado dirigidas hacia el ocaso/cénit o el solsticio de junio y azimuts pléyades (o 25 de mayo solar). En un número de casos (como en Turi, Catarpe y Viña del Cerro), la orientación este-oeste puede haber sido un tanto tosca y efectiva para el momento de construcción. Todavía podríamos notar que las similitudes en tamaño y conformación de las plazas en Catarpe, así como la orientación, son virtualmente idénticas a aquéllas de la doble plaza en Anocariri, un tambo cercano situado en Bolivia, cerca de Oruro (Hyslop 1984: 144, Fig. 9.4). Por otro lado, en Tambo Colorado, en el valle de Pisco, la cancha con habitaciones adjuntas es virtualmente la imagen de la cancha de Catarpe o kallanka (estructura 11) con los recintos asociados (estructuras 12 a 17) (Figura 6).

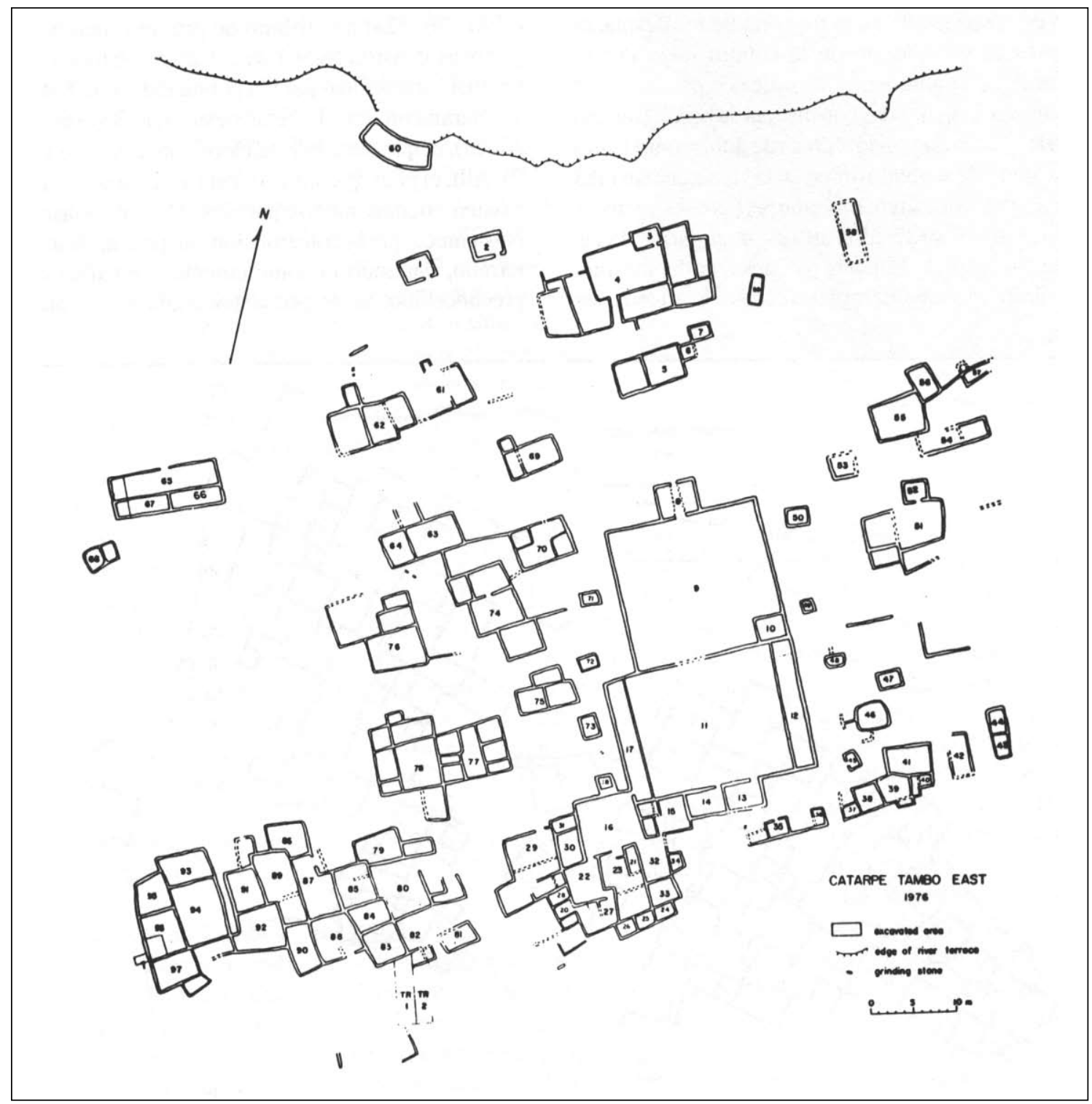

Figura 6. Sector este del Tambo de Catarpe y la ubicación de la doble cancha nuclear. 
Finalmente, debemos observar que los dos grandes recintos en Catarpe bien podrían ser considerados una plaza doble, orientada en ángulos rectos a sus plazas; aquí ambas están unidas por un acceso bien terminado y formal. Además, la plaza principal de Cusco tenía dos partes: hauhaypata y kusipata. Hyslop (com. pers. 1988) sugiere que muchas otras plazas incas (particularmente aquéllas fuera de la zona de Cusco) presentan evidencia física como un camino o un eje arquitectónico que las divide, generalmente cerca del centro. Una idea que vale la pena considerar es que la división de la plaza separa hanan de hurin.

El uso de mampostería en piedra finamente cortada es desconocida en la mayoría de los desplazamientos al sur y oeste de la cultura inca. Por el contrario, comúnmente son rústicas o parcialmente trabajadas, cementadas con mezcla de barro. Raffino (1981: 77) cataloga esta técnica de doble muro como un atributo de segundo orden en la construcción inca a través del Collasuyo. En Catarpe, los constructores incas y sus subordinados utilizaron guijarros de las bancadas locales. Muchas paredes aún demuestran sus alturas totales completas y por lo menos las largas estructuras subdivididas (12 y 17) estaban cubiertas con techos de paja. Esto constituye lo que puede ser la kallanka más sureña conocida.
Sin embargo, no es posible que grandes grupos viajaran regularmente al sur, dentro del despoblado carente de agua, de modo que Catarpe pudo haber tenido funciones importantes de almacenamiento y diligencia con la población local. Las habitaciones de almacenamiento 13 hasta 15 , y las obras de defensa cerca del perímetro del sitio, sugieren que Catarpe contuvo bienes de valiosa protección y suficiente personal estable.

Aberturas o "troneras" en algunas murallas son tanto una posible señal de defensa como para Raffino (1981: 76, 124) un atributo de primer orden de los patrones constructivos incas. Catarpe también fue un área habitacional para la población local. Esto se ve claramente en el sector oeste del sitio (tal vez hurin), el que tiene más núcleos constructivos (Figura 7). Allí, el plan de construcción fue menos regular y existen además menos paredes o muros masivos. Nos parece que la construcción fue para ajustarse al terreno, variando el sometimiento a un plan muy preconcebido. Se sospecha que algún asentamiento local pudo haber precedido, así como también pudo coincidir o ser inducido por la ocupación inca a servir en Catarpe. Las excavaciones realizadas en el sector este expusieron dos restos de paredes o muros tempranos que yacían discordantemente bajo las estructuras planificadas

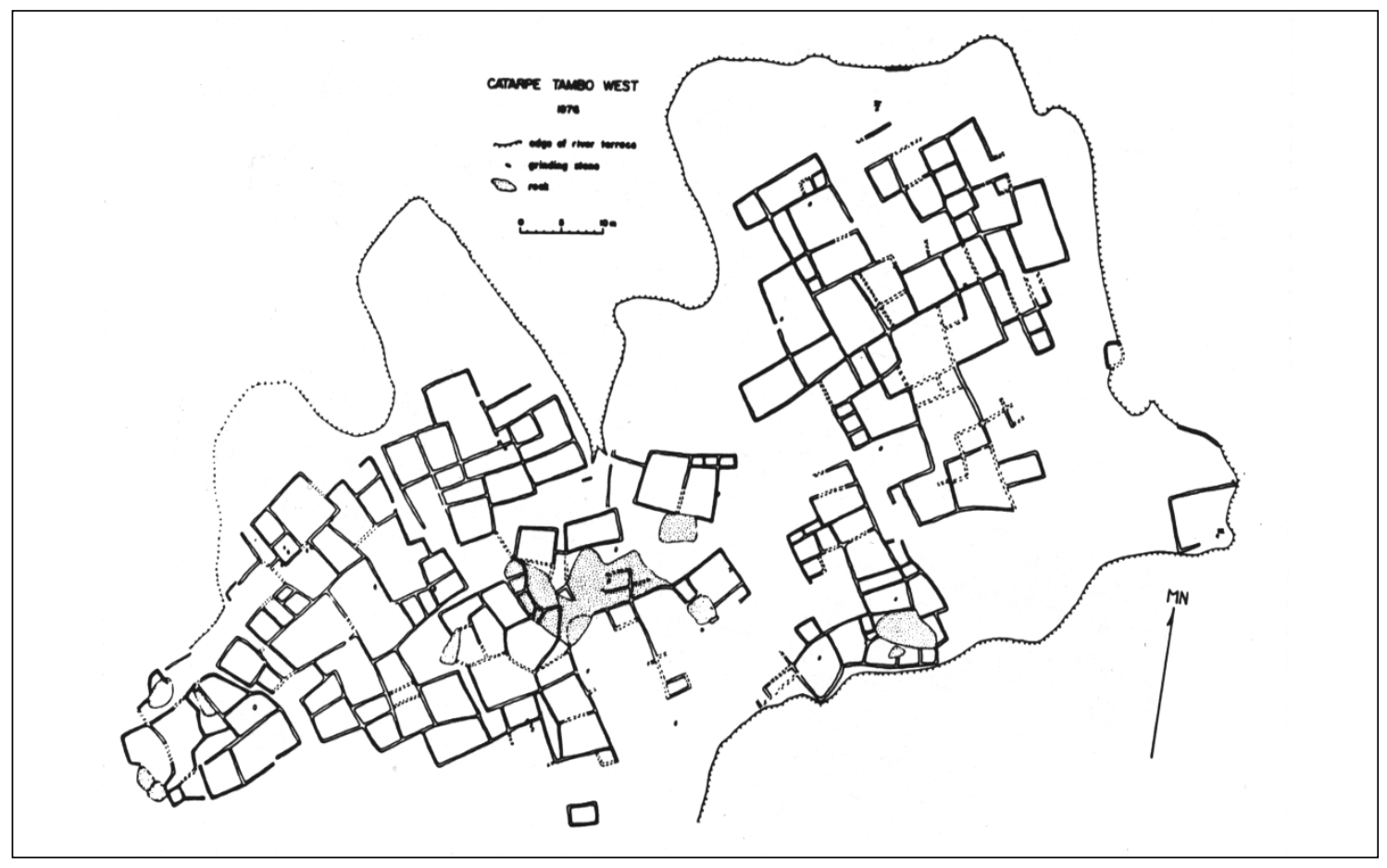

Figura 7. Sector oeste del Tambo de Catarpe. 
por los incas. También cabe destacar, excepto en el cementerio, que los tiestos incas, incluso los fragmentos incas provinciales son extremadamente extraños, aunque incluyen algunos grandes jarros de cuello estrecho (aríbalos), que simbolizan la uniformidad inca y las actividades relacionadas con el Estado (Carlevato 1988: 44). Si debemos seguir el consejo de Hyslop (1984: 22) para evitar la confiabilidad de la arquitectura en términos de identificar el fenómeno "tambo", ubicaríamos a Catarpe a través de sus cucharas de madera y sus torteras de huso mucho más que por su alfarería.

Es posible que esta situación sea análoga a la interpretación de las frecuencias de polen en sitios donde el polen transportado por el viento, proveniente de productores prolíficos, puede recargar la lluvia local de polen. En otros sitios, y así se discutirá a continuación, la alfarería inca es, contrario a Catarpe, relativamente común. Domina aquí la situación de borde u orilla de camino, en donde la población local previamente era insignificante o estaba ausente. Los simples tambillos o chasquihuasi son claramente menos incas en cuanto a conformación, orientación y disposición del sitio y, por supuesto, los materiales locales son utilizados convenientemente en estas construcciones. Una excepción a esto es la terminación algo más fina de los muros de los recintos de Peine, Meteorito, Puquios y Guanaqueros.

Por otra parte, debemos identificar estas construcciones incas principalmente por sus artefactos asociados, incluyendo el camino o sendero en sí, tal como lo sugirió Hyslop. Cerca de la entrada a Catarpe, el camino es un "artefacto" de buena definición, debido a que se asemeja a escalones bien definidos, raro en el Collasuyo, los que constituyen una excelente señal de la construcción inca, así como de su uso dado por los incas (Raffino 1981: 77; Figura 8).

Otros tambos y el camino del sur

El próximo tambo situado al sur de Catarpe se ubica en Peine, y fue descrito por Niemeyer y Rivera en 1983. Como la distancia es cercana a los $100 \mathrm{~km}$, existieron probablemente dos lugares de descanso intermedios, hasta ahora no identificados. El primero puede haberse ubicado en Toconao o la Quebrada de Aguas Blancas, ambos buenas fuentes de agua y el segundo, tal vez, bajo Socaire. El tambo Peine está bien construido en piedra, en algunas ocasiones

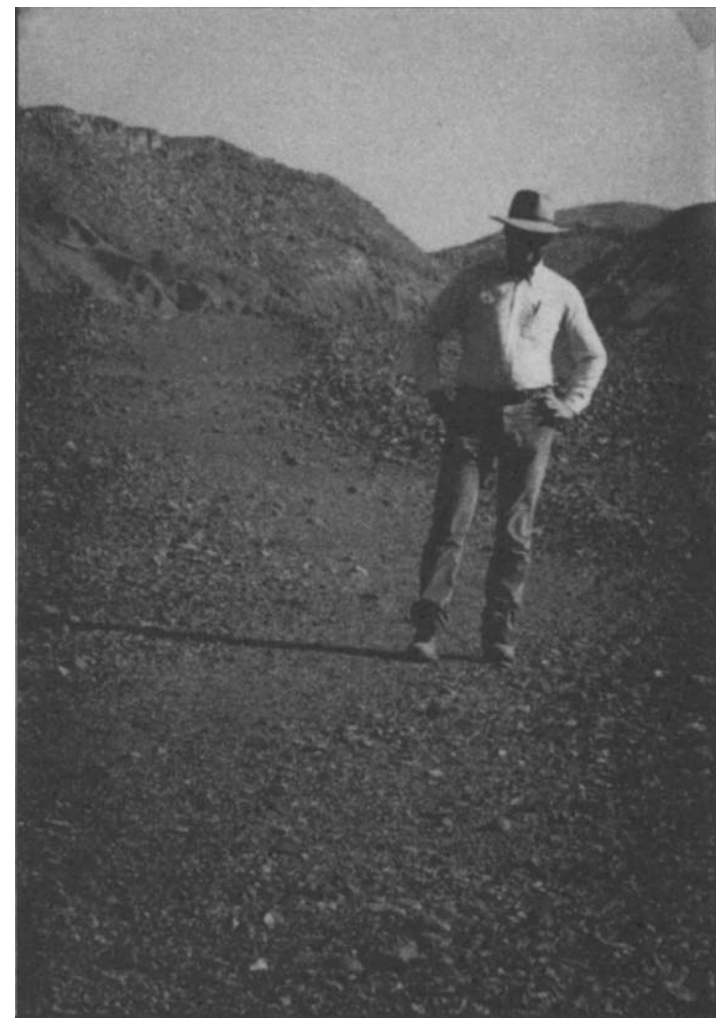

Figura 8. Camino inca cercano al Tambo de Catarpe. Se advierte despejado originalmente sin intervenciones posteriores.

con dos hileras, dispuestas con la parte frontal hacia afuera (Figura 9). Sin embargo, también es un poco pequeño, consistente en siete recintos dentro de un área amurallada de $60 \times 15 \mathrm{~m}$. Al igual que Tambo Salado y Catarpe, domina desde lo alto un curso de agua y, desde su pequeña elevación sobre una colina, tiene una vista que cubre el camino más próximo. Distinto a Catarpe, este tambo no está fortificado y tiene fácil acceso. Tanto el equipo del Camino del Inka como nosotros, recolectamos alfarería inca y restos de turquesa.

El Tambo Meteorito se encuentra a una altura de $3220 \mathrm{~m}$ y unos $840 \mathrm{~m}$ más alto en relación a Peine, a medida que los caminos se empinan en dirección al sur, saliendo de la cuenca de Atacama. A pesar del optimismo de Hyslop, sería una muy difícil caminata, cercana a los $44 \mathrm{~km}$ para un solo día de jornada. De este modo, calculamos una parada intermedia, en Tilomonte, junto al Camino del Inka, en donde existe un bosquecillo de algarrobo y recintos de data eventualmente de esta época, en el entorno de un árbol grabado por algún misionero 


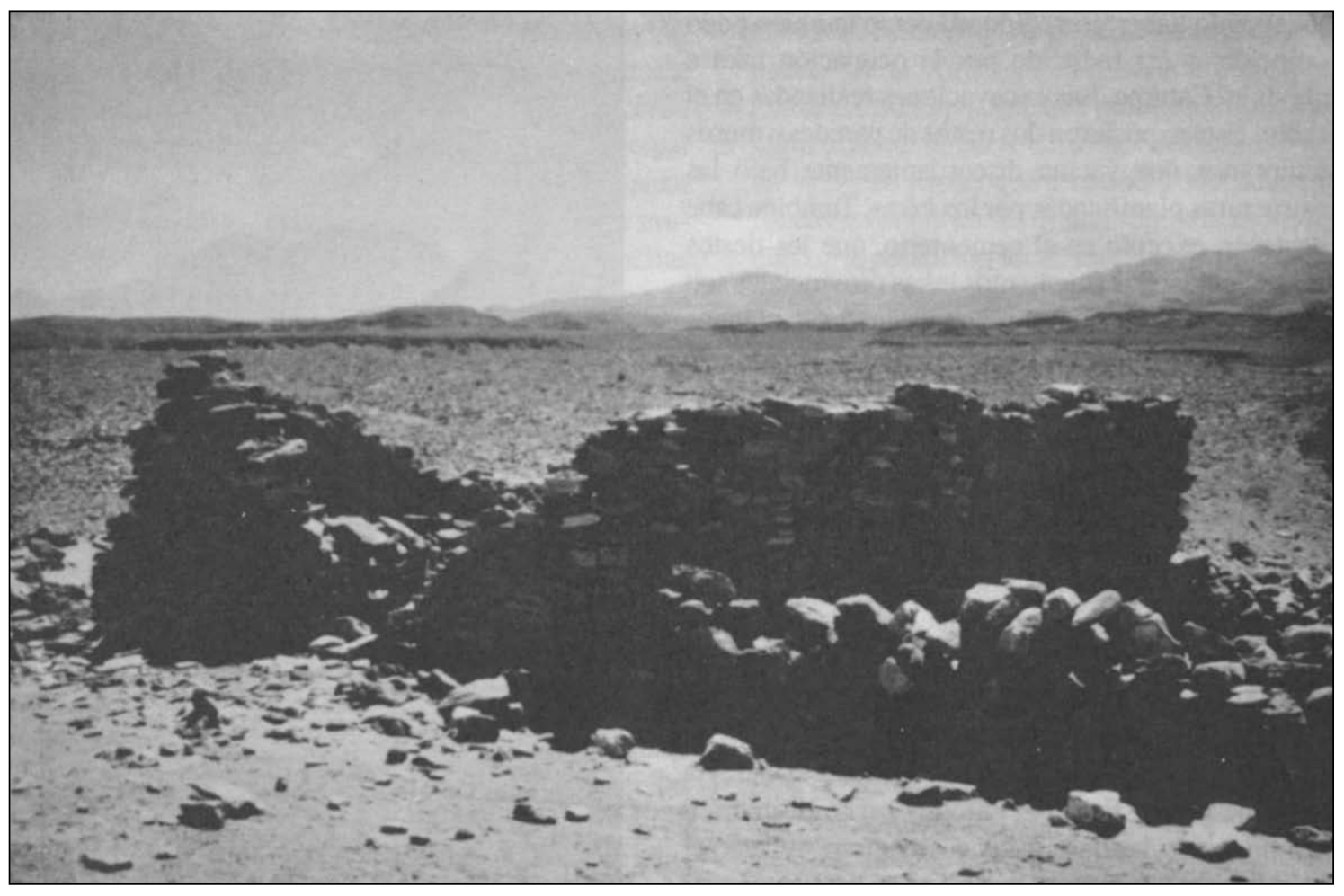

Figura 9. Detalle de las estructuras del Tambo de Peine.

en el siglo XVII, pero efectivamente no se ha ubicado aquí un tambo propiamente tal (Hyslop 1984: 154). El Tambo Meteorito también posee siete u ocho cuartos sobre un área de aproximadamente $60 \times 10 \mathrm{~m}$, situado en una llanura abierta, sin recurso de agua y sin ningún esfuerzo aparente para prevenir el acceso. Los métodos de construcción son como los de Peine, pero en Meteorito se ha conservado un acceso trapezoidal con dintel monolítico. El dintel es similar a uno caído ubicado esta vez en la entrada a la cancha de Catarpe. El equipo del Camino del Inka colectó fragmentos incas y coloniales tempranos en tambo Meteorito. Desde Meteorito a un posible tambo en la aguada de Puquios (3730 m en la Sierra de Almeyda) se extiende otro viaje muy difícil de $42 \mathrm{~km}$, pero se ha identificado un refugio intermedio en Neurara $(3350 \mathrm{~m})$, donde Niemeyer recolectó alfarería inca y colonial. Se constituye de no más de un cuarto, configurando un "tambillo" poco impresionante. En efecto, el único recinto de Puquios mide tan solo 2.5 por $2.1 \mathrm{~m}$ y no nos atreveríamos a clasificarlo como un tambo. No obstante, se trata de una estación bien construida, a la manera acostumbrada de los incas, porque incluso tiene una entrada monolítica.
El patio adjunto y amurallado tiene una estructura rectangular y una entrada con cuatro gradas. Los únicos artefactos pequeños identificables fueron dos puntas de proyectiles tetragonales de tipo precerámico. Niemeyer supone que hay depósitos de inundaciones provenientes de la quebrada, los que habrían cubierto el centro inca. Por otro lado, Hyslop (com. pers. 1987) ha informado al primer autor que el sitio de Puquios fue parcialmente desmantelado y destruido por el tráfico de camiones pesados que cargaban agua desde los manantiales.

Desde la aguada de Puquios bajando y atravesando el salar de Punta Negra hay un tramo de 65 a 70 km, pero existe un sinnúmero de quebradas protegidas con buenas aguadas así como también un manantial en la punta extrema del flujo de basalto Punta Negra (Figura 10). En un viaje en mulas Niemeyer, Schmidt y P. Núñez se demoraron dos días para llegar a la quebrada de Zorras. La primera noche acamparon en la parte superior de la quebrada Pajonales, cabalgando dos horas en la mañana siguiente hasta el Pajonal principal, con recurso de agua, pastos y una construcción perteneciente a la época histórica. Aparentemente, perdieron el 


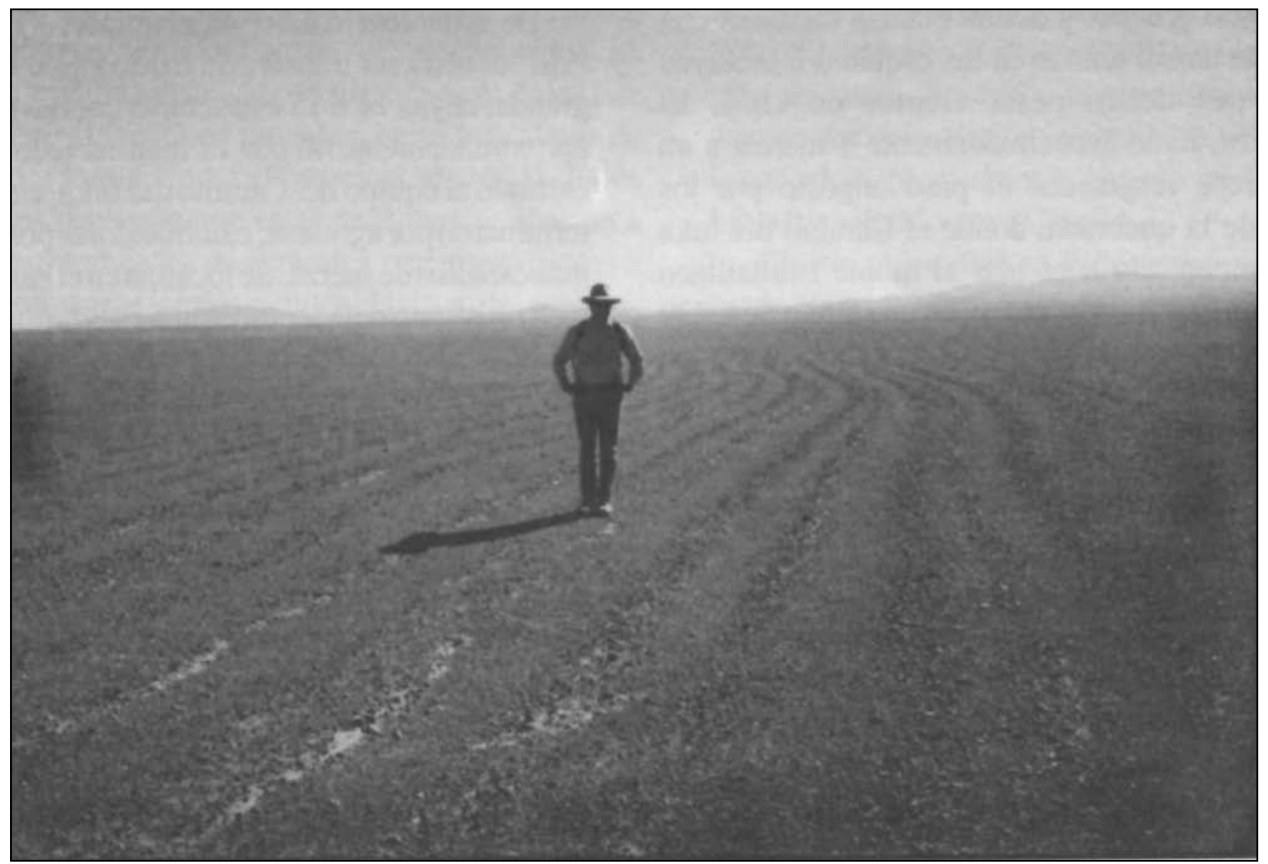

Figura 10. Camino de caravanas de data inca en el piedemonte oriental del salar de Punta Negra, sin señales de uso reciente.

acceso al Camino del Inka, fuera de la quebrada Pajonales, donde se desvía hacia el sur en el tributario Vizcachas de la quebrada Guanaqueros. Esta sección fue identificada y recorrida por el equipo de la Universidad de Cornell en los años 1985 y 1988 . Se propone que la principal parada inca pudo no haber sido Pajonales, como lo indicó el guía del equipo del Camino del Inka, sino por quebrada Guanaqueros, donde en 1985 el primer autor localizó otra entrada de dicho camino proveniente del norte. En el fondo de la quebrada existe un tambo situado estratégicamente, con varios cuartos (por lo menos siete), algunos reconstruidos, incluyendo una collca circular y un clásico chasquihuasi de lados abiertos, construido de la correcta manera inca (Figura 11). Las paredes son gruesas y tienen buenas fachadas con mezcla de barro, unidas en las esquinas e incluyen piedras que deben pesar cientos de kilos. El chasquihuasi tiene aproximadamente $3 \mathrm{~m}$ a un lado, parece resguardar el paso angosto por las paredes de la quebrada, donde el Camino del Inka habría comenzado a escalar el monte Llullaillaco desde los $3500 \mathrm{~m}$ de altura. Con una altura de $6739 \mathrm{~m}$ (6780 m, en otras fuentes) esta notable montaña es la tercera más alta en el hemisferio occidental, y por cierto fue un lugar sagrado para los incas, en cuanto está coronada por un altar descrito por Reinhard (1983). El tambo Guanaqueros, que descansa en el fondo de la quebrada, ha sido afectado innumerables veces por inundaciones. No había fragmentos cerámicos incas en la superficie, pero descubrimos cuatro piezas negras sobre rojo, en el difícil camino que desciende desde el borde de la quebrada norte. Parece que pertenecen a la tradición Saxamar inca/provincial y/o al estilo Copiapó Negro sobre Rojo.

La distancia en línea recta es de tan solo $42 \mathrm{~km}$ desde Guanaqueros al reducido manantial potable localizado en Punta Negra, a 2950 m, donde también han sido colectados fragmentos incas. Esta es la distancia máxima que advierte Hyslop entre los tambos del área. Desde Punta Negra a un tambo de aproximadamente 15 cuartos cercano a la boca de la quebrada Río Frío existen otros $42 \mathrm{~km}$, por una leve inclinación que asciende a $3600 \mathrm{~m}$ de altura. No existen fuentes de aguas intermedias, salvo a lo largo de la senda de una pequeña desviación, en Barrancas Blancas. Allí el grupo de Niemeyer descubrió algunos fragmentos (identificados como Inca y Copiapó Negro sobre Rojo), asociados a refugios de roca amurallada y muy pequeños de marcado formato incásico.

El Tambo Río Frío descrito por Niemeyer tal vez no sea un tambo o tambillo. Se trata de una estructura única, más o menos rectangular de aproximadamente 


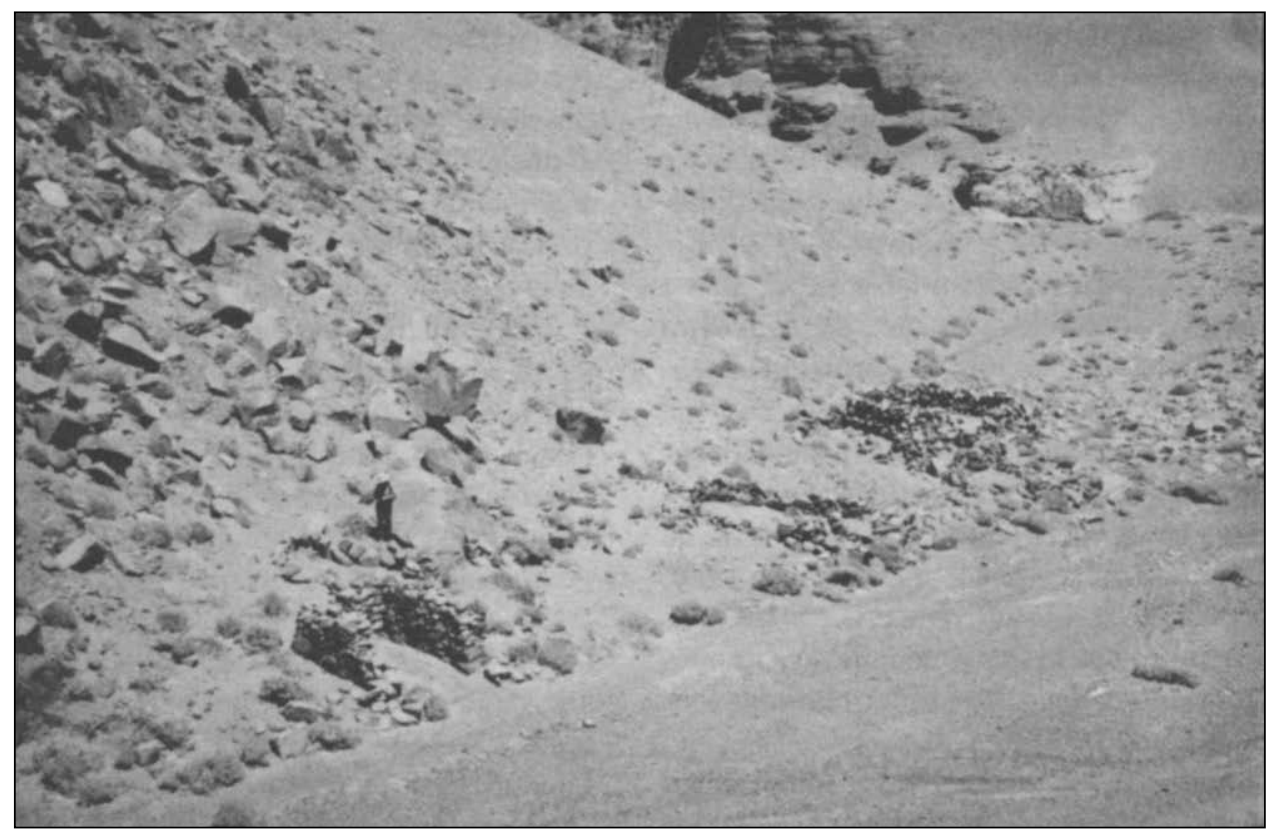

Figura 11. Panorama del Tambo de Guanaqueros, cerca del volcán Llullaillaco.

$3 \mathrm{~m}$ por un lado, la que posiblemente no fue techada. Los pocos fragmentos asociados pertenecían a la serie no-inca de San Pedro, con la excepción de una pieza moderna de vidrio y un fragmento de borde de una atípica escudilla inca (Niemeyer 1983: 125). Este refugio ha sido utilizado con más frecuencia en los tiempos coloniales y modernos y, después de la colección total de superficie realizada por Niemeyer, el equipo del primer autor también ocupó el lugar. Está protegido del viento y fue el único refugio detectado a una gran vista orientada al monte Llullaillaco.

De acuerdo a lo anterior, el nombre Tambo Río Frío debería ser transferido a otro sitio mucho más grande, cuyas 14 ó 15 estructuras cubren un área de aproximadamente $40 \times 12 \mathrm{~m}$. Este lado se le extravió al equipo del Camino del Inka, cuyas mulas terminaron por agotarse, cambiándolas por jeeps con más caballos de fuerza. Se localiza en el lado sureste, bien protegido del viento, en una colina que separa la quebrada Río Frío de la quebrada Laguna Seca. En este sitio libre de disturbios, el primer autor colectó grandes cantidades de alfarería inca, una punta inca de obsidiana, restos de turquesa e incluso un hueso quemado. Con la excepción de un gran cuarto o plaza, la configuración del Tambo Río Frío, o mejor, Laguna Seca, no es marcadamente inca en su formato arquitectónico.
Las paredes están construidas pobremente de rocas como planchas planas puestas una sobre la otra, en donde la mayoría de las estructuras son claramente subrectangulares. Sin embargo, el sitio merece una mayor investigación, porque hay restos de estructuras y cerámica multicomponente con áreas de actividades no aglutinadas que lo hacen algo diferente del patrón inca clásico (Fuentes et al. 1991). Aunque allí el primer autor logró una colección superficial exhaustiva, el segundo, junto a C. Santoro ubicó, posteriormente, el tablero de aluminio de la Misión Lynch y otros fragmentos cerámicos dentro de los cánones registrados previamente.

Aparte de estos tambos, situados en el principal Camino del Inka, existen numerosas apacheta, hitos o marcas consistentes en rocas acumuladas, dispuestas en pares, en ambos lados del camino. Algunas todavía están apiladas elegantemente como columnas. La figura inolvidable de Hyslop que indica que el ancho del camino de Atacama es del orden de los $3 \mathrm{~m}$, representa un buen promedio para el principal camino por el lado este del salar de Punta Negra.

Sin embargo, también hemos identificado otro camino, esencialmente no estudiado, que corresponde a uno angosto, que recorre el lado oeste del salar de Punta Negra, al sur del salar de Imilac. 
Aquí hemos observado considerables cantidades de turquesa y fragmentos de tiestos preincaicos de la tradición San Pedro pulido, asociados a pequeñas estructuras, así como también ocasionales fragmentos incas. Es muy seguro que el camino de Imilac, que se extiende a lo largo del lado este del salar de Punta Negra, representa una ruta anterior al "nuevo" Camino del Inka.

Posteriores estudios del segundo autor con el colega C. Santoro han ratificado las suspicacias del primer autor, en cuanto descubrieron la ruta preinca orientada al Pacífico. En efecto, el registro de senderos preincaicos en el "despoblado" de Atacama se ha ratificado con los hallazgos de más de 10 loci de recintos pircados, entre los salares de Imilac y Punta Negra (Fuentes et al. 1991). Estos estudios probaron que estas paskana se asocian a rutas y fragmentos de cerámica correspondientes a los tipos negros y rojos pulidos clásicos, del comienzo de la era, incluyendo otros en secuencia que culminan con el tipo rojo pintado inmediatamente preincaico. Estas rutas ponían en contacto los oasis atacameños con el litoral entre Paposo y Taltal.

La existencia de caminos preincas al litoral de Taltal, sugiere que antes de los incas, atacameños y copayapos estaban en contacto a través de una ruta. Esto significa que la viabilidad inca se basó en un trazado previo ya usado por los pueblos atacameños y copayapos (estilo cerámico Copiapó Negro sobre Rojo), quienes articulaban un amplio territorio de interacción. Aún durante la resistencia antiespañola del siglo XVI se reconocen contactos y viajes entre los oasis de Atacama y el valle de Copiapó.

\section{El Tambo de Collahuasi}

Una reciente exploración del segundo autor en las tierras altas de quebrada de Guatacondo, donde se ubica el distrito minero-cuprífero de Collahuasi, permitió esclarecer los vínculos más norteños de la conexión Catarpe-Turi descrita anteriormente, a través de la localización de un nuevo yacimiento inca ubicado en el extremo sur del altiplano tarapaqueño: Collahuasi.

De acuerdo a la literatura se han ubicado los centros administrativos incaicos más densos en las tierras altas tarapaqueñas en el extremo septentrional, correspondiente a la serranía ariqueña (Dauelsberg 1983; Santoro 1983). Entre estos centros y el comparable más cercano: Turi, median ca. 500 km (Figura 12), con vestigios incaicos menores, como un cementerio con estructuras sencillas en el Tojo, localizado en la cabecera del valle de Collacagua (Niemeyer 1963) o el camino empedrado por laguna del Huasco al interior de Pica (Núñez 1965).

Se debe a la genial intuición de Mostny (1948) la ubicación de un punto medio en esta ruta, basado en la ubicación cartográfica de un cerro llamado Pabellón del Inka, cercano a la estación férrea Ujina, junto a la frontera boliviana, en la cabecera altoandina de quebrada Guatacondo (distrito minero Collahuasi). Por lo mismo, reconoció en la localidad de Ujina un eventual sitio inca que no había sido identificado en su oportunidad. Siguiendo a Mostny (1948), cuando Raffino (1981) traza el camino inca de altura, establece la conexión tarapaqueña-atacameña: Tojo-Huasco-Ujina-MifioTuri-Catarpe-Licancabur, precisamente basado en la referencia hipotética de Mostny (1948).

El sitio se localizó en la banda sur de la desembocadura de quebrada Yabricoyita, hacia la cuenca que domina el cerro Pabellón del Inka, junto al camino principal (4300 m.snm), apegado a los cerros, que conducen al salar de Coposa desde Collahuasi (Figura 13A).

El espacio construido está delimitado por el pie del barranco y un lecho seco (Figura 13B), que se reactiva estacionalmente. $\mathrm{Al}$ otro lado del lecho seco (NE), sólo se registra un recinto aislado, vinculado al afloramiento rocoso utilizado como cantera y varias collca dispersas ubicadas aguas arriba del recinto referido.

En la superficie de sus nueve unidades arquitectónicas (3377 m² de ocupación) se advierten restos de cerámica decorada de filiación inca imperial cusqueña y provincial, procedentes del altiplano boliviano (Inca Pacajes o Saxamar), incluyendo varios tipos domésticos monocromos más dominantes.

La arquitectura presenta el clásico formato inca, como los recintos con muro perimetral compuesto, nichos trapezoidales intramuro, plantas de recintos trapezoidales, patios con silos agregados, plaza o patio central, conjunto de collca o bodegas aglutinadas en "media luna" y collca circulares aisladas, etc. Corresponde a un programa arquitectónico definido para acoger labores de marca (actividades permanentes) y funciones de tambo (caravaneo 


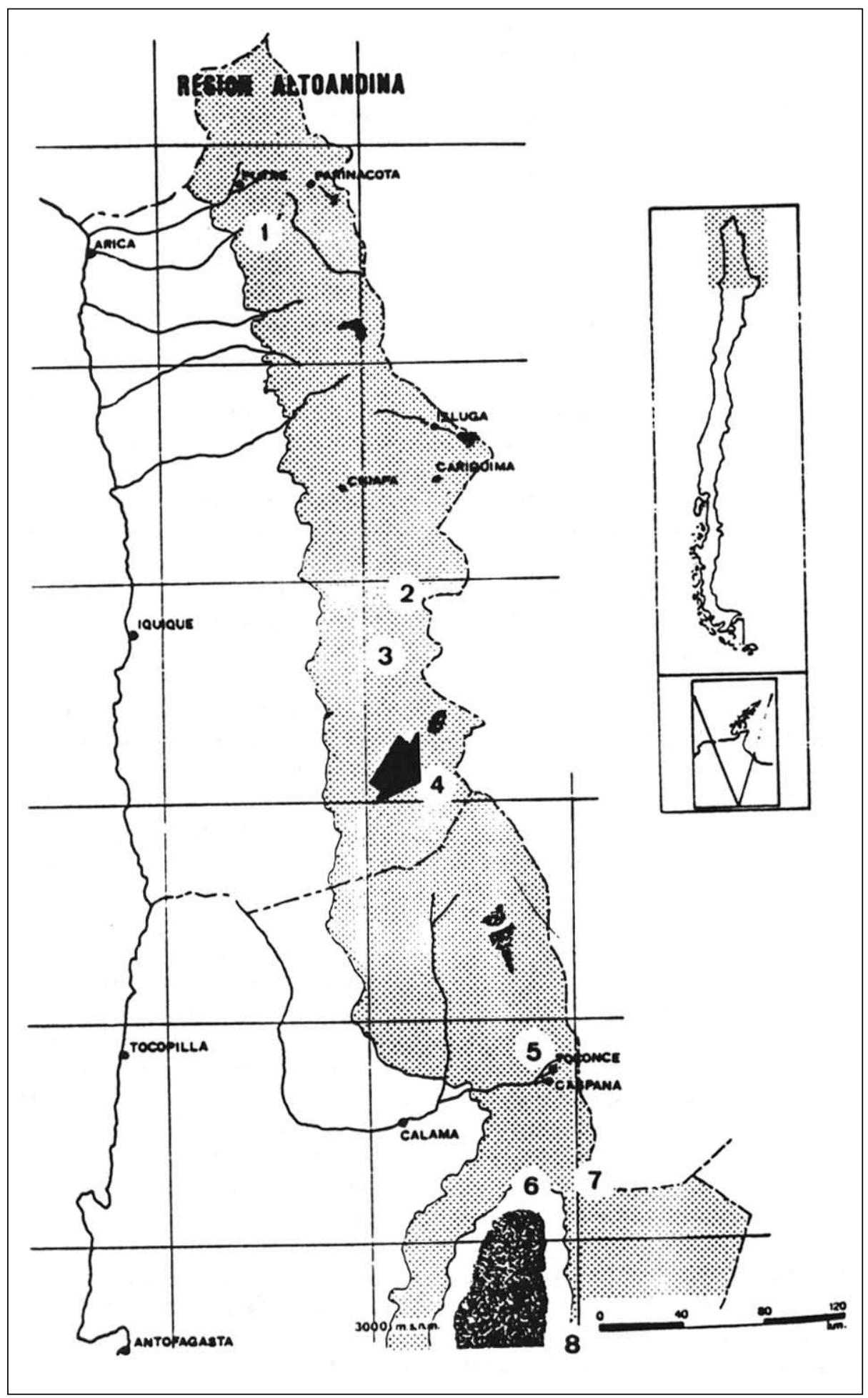

Figura 12. Ubicación del sitio Collahuasi en las tierras altas del norte de Chile: 1) Asentamientos incas de la Sierra de Arica, 2) El Tambo de Collacagua; 3) Camino inca del salar de Huasco; 4) Marca-Tambo de Collahuasi; 5) Marca-Tambo de Turi; 6) Marca-Tambo de Catarpe; 7) Marca-Tambo Licancabur; 8) Marca-Tambo de Peine (centros administrativos). 


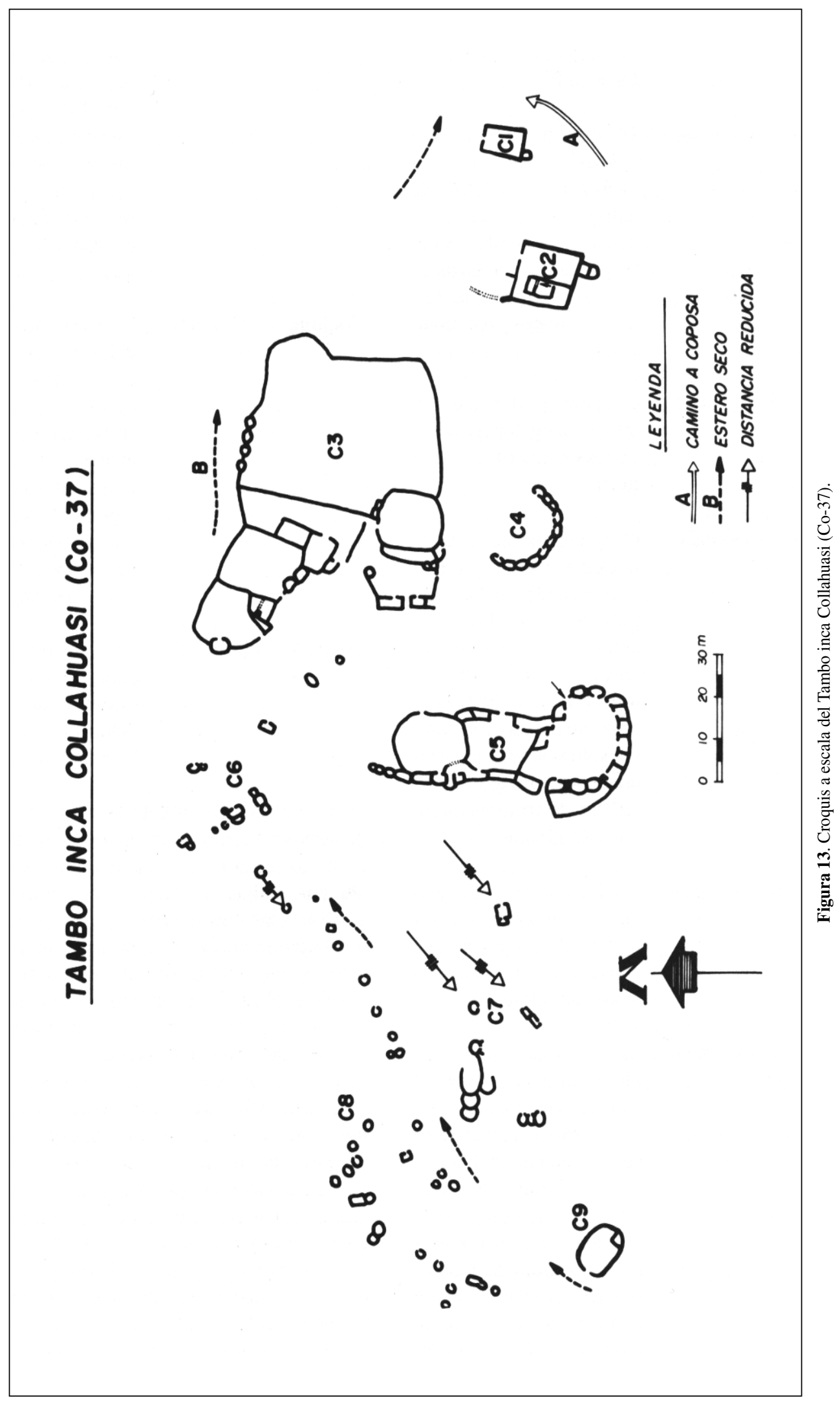


itinerante). La presencia de restos de minerales, pisos con ceniza y la toponimia quechua en las altas cumbres aledañas, hacen pensar que los incas explotaron cobre y oro en los filones superficiales de Collahuasi acorde con su expansión al sur, tras el incremento de bienes metálicos y piedras preciosas comunes en los Andes del Sur.

Al observar el plano de campo provisorio se advierten nueve unidades arquitectónicas bien definidas:

Conjunto 1 : Recinto residencial rectangular con $\left(50.5 \mathrm{~m}^{2}\right) \quad$ collca agregada al exterior.

Conjunto 2 : Recinto residencial perimetral com$\left(161.8 \mathrm{~m}^{2}\right) \quad$ puesto por collca al interior y exterior excluyendo una zona de expansión inconclusa hacia el noreste.

Conjunto 3 : Ubicación de una gran plaza o $\left(2.206 \mathrm{~m}^{2}\right)$ patio nuclear $\left(1317 \mathrm{~m}^{2}\right)$, rodeada de aglomeraciones de tres residencias eventuales, tres patios menores y cerca de 12 collca agregadas, de formas circulares y rectangulares.

Conjunto 4 : Conjunto de 11 collca circulares $\left(38.5 \mathrm{~m}^{2}\right) \quad$ apegadas, concentradas en un orden "semilunar".

Conjunto 5 : Conjunto perimetral compuesto $\left(650 \mathrm{~m}^{2}\right) \quad$ por collca circulares y cuadrangulares del patrón "semialunado", apegadas, tres espacios interiores liberados o patios, rodeados de collca laterales. Se reconocen sólo seis recintos residenciales y un total de 22 collca de forma circular dominante.

Conjunto 6 : Conjunto de 16 collca aisladas, de $\left(41.0 \mathrm{~m}^{2}\right) \quad$ planta circular y rectangular, algunas apegadas y cercanas a los conjuntos anteriores.

Conjunto 7 : Este conjunto no está visible desde $\left(78.8 \mathrm{~m}^{2}\right) \quad$ el acceso por el camino principal. En efecto, el primer recinto de su sector derecho da inicio a la parte "oculta" del asentamiento. Se compone el conjunto de tres recintos subrectangulares dispersos de probable función residencial con aglomeraciones de collca. Hay además otras tres semicirculares apegadas y aisladas al pie del principal afloramiento rocoso y una última aislada de menor tamaño. En el plano referido este conjunto presenta una distancia acortada para los efectos de edición (ver líneas aserradas), y se introduce en el giro suroeste de la quebrada, aguas arriba.

Conjunto 8 : En este sector, al otro lado del lecho $\left(74.5 \mathrm{~m}^{2}\right) \quad$ seco, a través de una extensa colina que desciende a la quebrada, se localizaron 31 collca aisladas, circulares y ovales, y en sólo tres casos algunas de paredes rectas. Están distribuidas de manera dispersa, con algunos casos apegados en par.

Conjunto 9 : Al final del Conjunto 7, aguas $\left(76.0 \mathrm{~m}^{2}\right) \quad$ arriba, se ubicó un último recinto con una bodega interior, posterior a la estructura original.

Un análisis preliminar da cuenta de fragmentos de tiestos polícromos provenientes de la región nuclear cusqueña y de los centros administrativos del altiplano boliviano. Es típica la cerámica Inca Pacajes y/o Saxamar con llamitas negras estilizadas. Hay otros tipos polícromos de las tierras altas poco conocidos, al tanto que se constataron escasos fragmentos de la Cultura Pica, de data preinca, que convivió con el régimen imperial. La tradición cerámica negro sobre rojo de llamitas y motivos geométricos (Khonko-Collao) es similar a los registros Saxamar de los centros de la Sierra de Arica y del pie del Licancabur, involucrada con un circuito vial que integraba las marca administrativasmineras y tambos del centro-sur de Bolivia con las comarcas tarapaqueña y atacameña, incluyendo la Puna jujeña/Quebrada de Humahuaca y el norte del valle Calchaquí.

Observando la planta del sitio parecería que se está en presencia de un asentamiento cuyas funciones no se correlacionan con la definición clásica de tambo, a juzgar por su alta diversidad de funciones. Su localización se vincula con varios acondicionamientos básicos: a) pasadizo altiplánico natural para el flujo caravánico por la ruta altoandina; b) microclima de quebrada abrigada junto a la ruta asociada a un territorio plano y expuesto; c) cercanía de vertientes; d) recursos de cobre-oro de alta ley en superficie; e) forraje con vegas suculentas aptas para crianza y mantención de caravanas; f) cercanía a avifauna lacustre. 
De todos estos factores el minero parece ser el de mayor atracción, perfilándose como el locus metalífero intermedio o el número 11, de los 10 descritos por Raffino (1981) en el área in toto, básicamente entre las evidencias del valle de Camarones y el Loa Superior.

La alta frecuencia de collca circulares usualmente dispersas acercan estas evidencias a los sitios más privilegiados por el régimen de almacenamiento acorde a los yacimientos de Bolivia como Incallajta, o los argentinos de Rinconada de Casabindo e Incahuasi de Lagunillas. En el norte del país se compara con el bodegaje de la Sierra de Arica, Turi, Licancabur y Peine.

En tanto no se ha registrado población local estable y densa preinca, la marca-tambo de Collahuasi no se dispone sobre asentamientos preexistentes como ocurrió en Turi y Catarpe, aunque les iguala tentativamente con similar capacidad de bodegaje. En este sentido el sitio Collahuasi carece de $\mathrm{ka}$ yanka o gran estructura de mojinete que tipifica a Turi. Es decir, en Collahuasi no se cumplió un rol político-administrativo, tal como ocurrió en Turi y Catarpe, al implantarse allí el régimen inca en un medio con población local y jerarquías políticas permanentes, dando lugar a una arquitectura de dominio, defensa y estatus, ausente e innecesaria en Collahuasi, en donde fuera del sitio inca sólo ejerce sus dominios la soledad y otro asentamiento menor y homólogo a los pies del Miño. ${ }^{3}$

Nuestro interés por el estudio del uso dado por los incas al gran despoblado de Atacama comenzó como un aspecto incidental, casi como un "subproducto" de nuestras investigaciones sobre la adaptación e historia de los asentamientos arcaicos en el ambiente postglacial temprano del Desierto de Atacama. Es decir, gradualmente nos ha interesado el continuum histórico, incluyendo los patrones de explotación pastoralista y mineros prehistóricos e históricos, para la comprensión del potencial y los variados niveles de habitabilidad de uno de los desiertos más extremos del mundo. Precisamente a través del actual Proyecto Inca, patrocinado por The National Geographic Society y la Universidad Católica del Norte, podremos diversos colegas detallar con más exactitud las innumerables evidencias a lo largo de la interacción ruta inca-asentamientos-despoblado de Atacama. Debe tenerse en mente que desde la última vez que se le siguió a pie por don Diego de Almagro, Pedro de Valdivia y otras huestes y mensajeros a lo largo de los siglos XVI y XVII (Magallanes 1912), tanto las huellas como los vestigios arquitectónicos $\mathrm{y}$ artefactuales han sufrido los efectos erosivos naturales. Ahora, la agresiva expansión de las labores mineras a una escala insospechada puede poner en peligro la conservación e investigación de éstos, los testimonios más indispensables para la mejor comprensión de la presencia inca en el norte de Chile.

Agradecimientos El primer autor agradece a The National Geographic Society (Grant 4654-91), a la Fundación Nacional de Ciencia (Grant BNS8418815) y al Fondo Jacob y Hedwig Hirsch por su ayuda financiera en los últimos 10 años. A Minera Escondida y Universidad Católica del Norte (Instituto de Investigaciones Arqueológicas y Museo, San Pedro de Atacama), por todas las atenciones recibidas en términos de equipos, consejos, personal y compañerismo por lo que estoy personalmente muy agradecido. Los estudios en curso del Proyecto Inca se realizan con la participación de los colegas John Alden, Agustín Llagostera, María Antonietta Costa y Lautaro Núñez. El segundo autor agradece a la Empresa Consultora Geotécnica, en especial a los ingenieros Roberto Lastrico y María Eugenia Parot, por el apoyo otorgado para prospectar el distrito minero Collahuasi. Igualmente a los ejecutivos de la Compañía Minera Collahuasi por las facilidades recibidas, en especial al geólogo Aquiles González. Finalmente a los ayudantes de tantas jornadas, Santiago Ramos y Luis Ramírez del Instituto de Investigaciones Arqueológicas y Museo de San Pedro de Atacama, por su apoyo en Collahuasi.

\footnotetext{
Una más reciente exploración al pie del Miño nos permitió identificar los dos grandes asentamientos incas intermedios a su vez entre Collahuasi y la cabecera de Turi, cuyas evidencias serán presentadas en otro artículo por el segundo autor.
} 


\section{REFERENCIAS CITADAS}

ASCUE, J., 1988. Hallan restos de uno de los últimos incas. El Comercio Año 148 (79038), marzo 16, Lima.

BIBAR, G. DE, 1966. Crónica y relación copiosa y verdadera de los reinos de Chile (1558). Transcripción paleográfica de I. A. Leonard. Fondo Histórico y Bibliográfico José Toribio Medina, Santiago.

CARLEVATO, D., 1988. Late ceramics from Pucara, Perú: An indicator of changing site function. Expedition 30 (3): 39-45.

CASTRO, V. y L. CORNEJO, 1990. Estudios en el Pucara de Turi, norte de Chile. Gaceta Arqueológica Andina 5 (17): $57-66$

DAUELSBERG, P., 1988. Investigaciones arqueológicas en la Sierra de Arica, sector Belén. Chungara 11.

DEARBORN, D., 1986. Review of Incahuasi: The New Cuzco Archaeoastronomy 9: 114-122.

FUENTES, E., L. NUÑEZ, C. SANTORO y C. LAMPERGIN, 1991. Salar de Punta Negra. Desafío, vida, gentes. Minera Escondida Ltda.

HENDERSON, J. S., 1987. Frontier at the crossroads. En Interaction on the Southeast Mesoamerican frontier, J. Robinson (Ed.), pp. 455-462. BAR International Series 327, Oxford.

1992. Variations on a theme: A frontier view of Maya Civilization. En New theories on the Ancient Maya, E. Danien y R. J. Sharer (Eds.), pp. 161-171. University of Pennsylvania University Museum, Filadelfia.

HIDALGO, J., 1972. Culturas protohistóricas del norte de Chile: El testimonio de los cronistas. Editorial Universitaria, Santiago.

HYSLOP, J., 1984. The inca road system. Academic Press, Nueva York

1985. Incahuasi: The New Cusco. BAR International Series 234, Oxford.

— 1990. Inca settlement planning. University of Texas Press, Austin.

HYSLOP, J. y M. RIVERA, 1984. An expedition on the Inca Road in the Atacama Desert. Archaeology 37: 33-39.

IRIBARREN, J. y H. BERGHOLZ, 1971. El Camino del Inka en un sector del Norte Chico. Actas del VI Congreso de Arqueología Chilena, pp. 22-265 (Santiago). Reedición en 1972 Colección "11 de Julio", Compañía de Cobre Salvador, Potrerillos.

LE PAIGE, G., 1972-73. Tres cementerios indígenas en San Pedro de Atacama y Toconao. Actas del VI Congreso de Arqueología Chilena, pp. 163-187. Santiago.

1978. Vestigios arqueológicos incaicos en las cumbres de la zona atacameña. Estudios Atacameños 6: 36-52.

LYNCH, T., 1978. Tambo incaico Catarpe-Este (informe de avance). Estudios Atacameños 5: 142-147.
1989. Regional interaction, trashumance, and verticality: Archaeological use of zonal complementary in Perú and Northern Chile. Anthropology 8: 1-11.

1990. Quaternary climate, environment, and the human occupation of the South-Central Andes. Geoarchaeology 5 (3): 199-228.

MAGALLANES, M., 1982. El Camino del Inka. Revista Chilena de Historia y Geografía 2 (7): 44-75.

MOSTNY, G., 1948. Ciudades atacameñas. Boletín del Museo Nacional de Historia Natural XXIV: 211-225.

NIEMEYER H., 1981. Dos tipos de crisoles prehispánicos del Norte Chico, Chile, Boletín del Museo Arqueológico de La Serena 17: 92-109.

NIEMEYER H. y M. RIVERA, 1983. El Camino del Inka en el despoblado de Atacama. Boletín de Prehistoria de Chile 10: $91-193$.

NIEMEYER H. y V. SCHIAPPACASSE, 1988. Patrones de asentamiento incaicos en el Norte Grande de Chile. En $\mathrm{La}$ frontera del Estado inca, T. Dillehay y P. Netherly (Eds.), pp. 141-179. BAR International Series 442, Oxford.

NUÑEZ, L., 1965. Desarrollo cultural prehispánico del norte de Chile. Estudios Arqueológicos 1.

1983. Paleoindio y Arcaico en Chile: Diversidad, secuencia y proceso. Editorial Cuicuilco, México D. F.

RAFFINO, R. A., 1981. Los incas del Collasuyu. Editorial Ramos Americana, La Plata.

REINHARD, J., 1983. Las montañas sagradas: Un estudio etnoarqueológico de ruinas en las altas cumbres andinas. Cuadernos de Historia 3: 27-62.

1985. Sacred mountains: An ethnoarchaeological study of High Andean ruins. Mountain Research and Development 5 (4): 299-317.

REINHARD, J. y J. SANHUEZA, 1982. Expedición arqueológica al altiplano de Tarapacá y sus cumbres. Revista de la Corporación para el Desarrollo de la Ciencia 2 (2): 17-42.

RIVERA, M. y J. HYSLOP, 1984. Algunas estrategias para el estudio del Camino del Inka en la Región de Santiago. Cuadernos de Historia 4: 109-128.

RUPPERT, H., 1984. Zur verbreitung und herkunft von Turkis and Sodalithin Präkolombischen Kulturen der Kordilleren. 30: 69-124, Baessler-Archiv NF 3069-124.

SANTORO, C., 1983. Camino del Inka en la Sierra de Arica. Chungara 10.

SILVA, O., 1977. Consideraciones acerca del Período Inca en la cuenca de Santiago (Chile Central). Boletín del Museo Arqueológico 16: 211-243.

STEHBERG, R. y N. CARVAJAL, 1988. Road system of the Inka in the Southern part of their Tawantinsuyo Empire. National Geographic Research 4 (1): 74-97. 